\title{
云南鱼类三新纪录及驮娘江鱼类的区系存在度分析
}

\author{
杜丽娜 ${ }^{1,2}$ ，黄艳飞 ${ }^{1}$ ，陈小勇 ${ }^{1, *}$ ，杨君兴 $1^{*}$ \\ (1. 中国科学院昆明动物研究所 云南 昆明 650223, 2. 中国科学院研究生院, 北京 100049)
}

摘要: 2005 年 8 月, 对云南富宁县驮娘江流域的鱼类进行了考察, 采集到鱼类标本 38 种, 发现云南鱼类 3 新记录: 胡鮈(Huigobio chenhsienensiss Fang)、宽头盘鮈 (Discogobio laticeps Chu, Cui \& Zhou)、圆体爬岩鳅 (Beaufortia cyclica Chen)。结合历史记录和中国科学院昆明动物研究所鱼类标本馆馆藏的驮娘江流域的鱼类标本, 对㭈娘江鱼类的目、科、属三个级别进行区系存在度分析。区系存在度分析显示: 一些世界性分布的科和属, 在 驮娘江分布的种类并不很多, 相反, 一些具有地方性分布和小的科和属, 其区系存在度相对较大。长臀鯔科 (Cranoglanididae) 为中国华南区一越南特有的科, 其区系存在度为 $100 \%$ 。结鱼属(Parator)和红鲌属(Erythroculter) 为单种属, 区系存在度为 $100 \%$, 结鱼属是中国特有属, 主要分布在珠江水系, 红鲌属鱼类主要分布在亚洲南部。 这些地方性分布的小科属更能反映本地区的鱼类区系特征，即亚洲亚热带淡水鱼类区系。

关键词: 云南; 驰娘江; 鱼类; 新纪录; 区系存在度

中图分类号: Q959.4 文献标识码: A 文章编号: 0254-5853-(2008)01-0069-09

\section{Three New Records of Fish in Yunnan and Analysis of the Value of Faunal Presence of Fish in the Tuoniang River}

\author{
DU Li-na ${ }^{1,2}$, HUANG Yan-fei ${ }^{1}$, CHEN Xiao-yong ${ }^{1, *}$, YANG Jun-xing ${ }^{1, *}$ \\ (1. Kunming Institute of Zoology, the Chinese Academy of Sciences, Kunming, Yunnan 650223, China \\ 2. Graduate School of the Chinese Academy of Sciences, Beijing 100049, China)
}

\begin{abstract}
In Aug 2005, scientists of the Kunming Institute of Zoology (KIZ) took a survey of the fish in Tuoniang River, Funing County, Yunnan, collecting 38 species of fish. Three species, Huigobio chenhsienensiss Fang, Discogobio laticeps Chu, Cui \& Zhou and Beaufortia cyclica Chen, are new records in Yunnan Province. According to the historical record and the Tuoniang River fish specimens preserved in the collection room of KIZ, the author tried to assess the Value of Faunal Presence (VFP) of fish in the Tuoniang River at the respective levels of Order, Family and Genus. Analyzing the VFP is one key to revealing the geographic characteristics of some faunas. The VFP analyses indicated that some worldwide-distributed families and genera had a small quota in the Tuoniang River. On the contrary, the VFP of some endemic families and genera turned out to be relatively high. Cranoglanididae is an endemic family in South China-Vietnam, with a VFP of $100 \%$. Parator and Erythroculter have one species, with a VFP of $100 \%$. Parator is endemic to China; it is distributed in the Pearl River, while Erythroculter is endemic to South Asia. These endemically distributed families and genera can better represent the characteristics of fish fauna in the Tuoniang River, which belongs to the Asian Subtropical Freshwater Fish Fauna.
\end{abstract}

Key words: Yunnan; Tuoniang River; Fish; New records; Value of Faunal Presence

20 世纪 60 年代之前, 云南富宁驮娘江、西洋 江的鱼类未见报道。20 世纪 60-80 年代, 《中国鲤 科鱼类志上卷》 $(\mathrm{Wu}, 1964)$ 、《中国鲤科鱼类志下卷》 (Wu，1977)累计记录云南鱼类 109 种, 分布在驮娘 江、西洋江的鱼类有 21 种, 如海南华鳊[Sinibrama melrosei (Nichols \& Pope)]、南方拟餐[Pseudohemiculter dispar (Peters)]、大眼红鮊 [Erythroculter hypselonotus (Lin)]等。

1985 年后, 随着《云南鱼类志上册》 $(\mathrm{Chu} \&$ Chen, 1989)、《云南鱼类志下册》(Chu \& Chen, 1990) 
的编纂和出版, 云南的鱼类开始有了较为完整和全 面的记录, 上册共记录鲤科鱼类 220 种和亚种, 下 册共记录鱼类 179 种和亚种。其中记录驮娘江、西 洋江鱼类 40 种, 包括一新种, 窄条光唇鱼 (Acrossocheilus stenotaeniatus Chu)。

驮娘江位于云南省文山壮族苗族自治州富宁 县内, 是中国喀斯特岩溶地区向越南北部喀斯特岩 溶地区过渡的关键地区(Gao, 2006)。特殊的地理位 置和气候条件, 使该地区具有较高的生物多样性。 目前, 对驮娘江鱼类的分布和组成并无详细的报道 及分析。因此, 本文旨在利用区系存在度的方法对 驮娘江鱼类组成进行分析, 了解驮娘江鱼类的分布 特征。

\section{1 研究区域环境概况}

㭈娘江(N $24^{\circ} 01^{\prime} 11.6^{\prime \prime}$, E $106^{\circ} 03^{\prime} 50.7^{\prime \prime}$ )位于 323

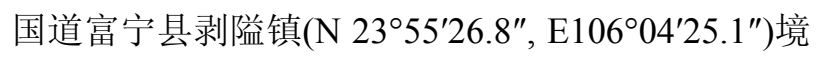
内, 发源于云南省广南县九龙山。它与发源于广南 县南部的西洋江平行并向东流淌, 在广西省田林县 合塘村东侧汇合南下流入富宁县境, 至百色后与乐 里河、澄碧河汇合 (称为右江), 右江与左江汇合 后又在广西桂平市注入珠江。驮娘江距富宁县城 $102 \mathrm{~km}$, 距广西壮族自治区百色市 $733 \mathrm{~km}$ (Gao, 2006)，主要支流有那马河、谷拉河等。

\section{2 材料与方法}

以《中国鲤科鱼类志上卷》 $(\mathrm{Wu}, 1964)$ 、《中国 鲤科鱼类志下卷》 $(\mathrm{Wu}, 1977)$ 、《云南鱼类志上卷》 (Chu \& Chen, 1989)、《云南鱼类志下卷》 $(\mathrm{Chu} \&$ Chen, 1990)、《广西淡水鱼类志》(Zheng, 1981)、《珠 江鱼类志》(Zheng, 1989)、《中国动物志中卷》(Chen et al, 1998)、《中国动物志下卷》(Chen et al, 2000)、 《中国条鳅志》(Zhu, 1989)、《中国淡水鱼类检索》 (Zhu, 1995)为基础, 查看中国科学院昆明动物研究 所馆藏的驮娘江一西洋江鱼类标本。2005 年 8 月, 在驮娘江江段及支流那马河、谷拉河和普厅河共设 7 个采样点 (图 1), 对整个驮娘江鱼类资源进行全 面调查。主要用刺网和电击两种方式对鱼类进行采 集, 并结合对周边市场鱼类的调查。此次野外调查 共采集到标本 567 号。在此基础上, 对驮娘江鱼类 目、科、属、种等不同层次进行统计, 分析其区系 的性质。据 Jiang et al（2000）的无量山哺乳动物区 系存在度概念来计算驮娘江鱼类的区系存在度：

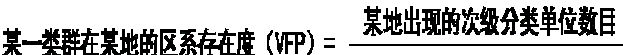 次级分类单位总数}

以此来分析驮娘江鱼类区系的特点。次级分类 单位总数数据来自 Fishbase (World Wide Web Electronic publication, 2007)。

\section{3 结果与讨论}

经参照历史记录、中国科学院昆明动物研究所 近十几年采集的标本记录, 确定了驮娘江流域共有 鱼类 74 种, 隶属于 4 目 15 科 56 属 (附录 I )。 在进行区系存在度分析时, 剔除了草鱼 [Ctenopharyngodon idellus (Cuvier \& Valenciennes)]、青鱼 [Mylopharyngodon piceus (Richardson)] 等经济性鱼类和尼罗罗非鱼 [Oreochromis nilotica (Linnaeus)]、子陵吻鰕鯱鱼 [Rhinogobius giurinus (Rutter)]等外来鱼类, 则驮娘 江土著鱼类有 61 种, 隶属于 4 目 12 科 45 属。

在 2005 年野外考察中, 发现 3 个云南省鱼类新记 录: 胡鮈(Huigobio chenhsienensiss Fang)、宽头盘鮈 (Discogobio laticeps Chu, Cui \& Zhou) 和圆体爬岩鳅 (Beaufortia cyclica Chen)。分述如下:

\section{1 物种分述}

3.1.1 胡鮈 Huigobio chenhsienensiss Fang, 1938(图

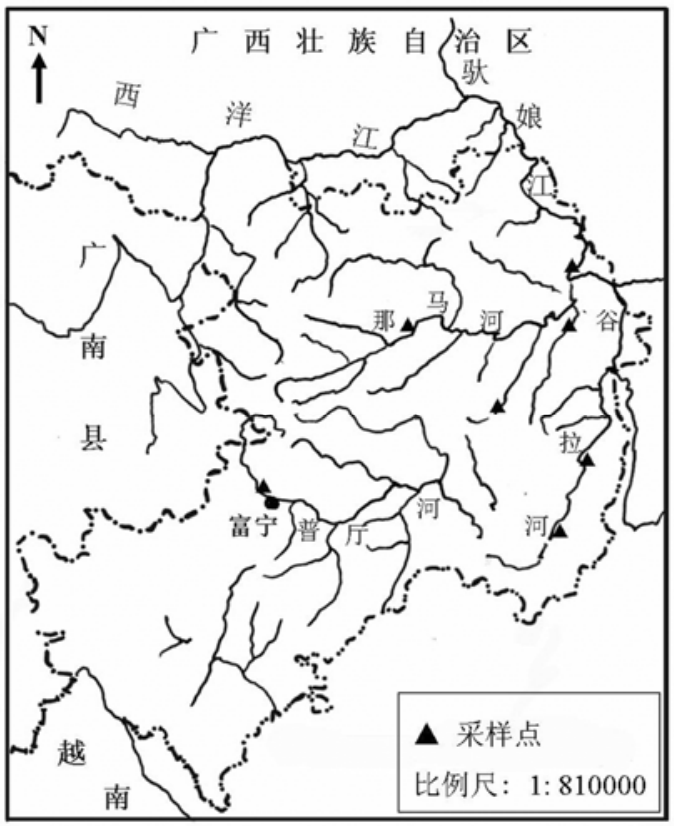

图 1 驱娘江流域鱼类采集地点图

Fig. 1 Map showing the sample site in Tuoniang River 
2) 采集标本 4 尾, 测量标本 4 尾, 全长 62.4 $67.5 \mathrm{~mm}$, 体长 48.2-53.5 mm。背鯺条 iii-7; 臀鯺 条 iii-5; 胸鯺 i-10-11; 腹鯺 i-7。侧线鳞 38; 围尾 柄鳞 12 。第一鳃弓外侧鳃耙 8 。体长为体高的 5.1 -6.6 倍, 为头长的 4.1-4.7 倍, 为尾柄长的 5.66.8, 为尾柄高的 $10.4-10.9$ 倍。头长为吻长的 2.8 -2.9 倍, 为眼径的 $2.9-3.4$, 为眼间距的 $3.8-5.2$ 倍, 为尾柄长的 $1.4-1.7$ 倍, 为尾柄高的 $2.4-2.7$ 。 尾柄长为尾柄高的 $1.6-1.8$ 倍。

体长, 粗壮。头小, 头长小于体高。吻短针, 鼻孔前方凹陷。口宽。唇厚, 布满乳突, 上唇中部 乳突大, 两侧乳突小; 下唇分 3 叶, 中叶为心形肉 质突, 两侧叶发达, 向后扩展似翼状, 上具细小而 密集的乳突。须 1 对, 极细小。眼大。

背鯺无硬刺, 其起点至吻端较距尾鳍基的距离 近。胸鯺长, 末端几乎达到腹鯺起点。腹鰙起点位 于背鯺起点之后。尾鰙浅叉形。

福尔马林、酒精浸泡的标本体背部深灰色, 腹 部灰白。横跨背部正中具 4-5 块不明显的黑斑, 体侧中轴有 9-10 个圆黑斑。侧线处由前至后具 1 黑条纹, 中轴黑斑均位于此黑纵纹之上。

分布于浙江的曹娥江、角江, 云南富宁驮娘江 及珠江水系的部分支流。

3.1.2 宽头盘鮈 Discogobio laticeps $\mathrm{Chu}$, Cui \& Zhou, 1993 (图 3) 测量标本 23 尾, 全长 58.7$134.4 \mathrm{~mm}$, 体长 $44.7-103.9 \mathrm{~mm}$ 。

背鯺 ii-8; 慰鯺 ii-5; 胸鯺 i-15; 腹鳍 i-8。侧
线鳞 39-40; 围尾柄鳞 16。第一鳃弓外侧鳃耙 22 。

体长为体高的 4.1-6.4 倍, 为头长的 3.6-4.4 倍, 为尾柄长的 $6.2-8.0$ 倍, 为尾柄高的 7.5-8.8 倍。头长为吻长的 $1.9-2.3$ 倍, 为眼径的 3.9-6.2 倍, 为眼间距的 $1.9-2.4$ 倍。尾柄长为尾柄高的 1.0 -1.4 倍。体长, 前部粗壮, 呈圆筒形。头宽, 略 大于头高。吻部圆, 无吻突, 吻端近背面具 1 对大 珠星，周围布满小珠星，较发达。

吻皮向腹面扩展, 盖于上领外面, 边缘分裂为 流苏状。吻皮与上领分离, 上唇消失。下唇形成椭 圆形吸盘, 口吸盘后缘后伸达眼中点的垂直下方。 眼侧上位。须 2 对。体鳞中等大。侧线平直。

背鯺无硬刺, 起点距吻端略小于至尾鯺基部。 尾鯺叉形。

福尔马林、酒精浸泡的标本体呈灰黑色, 腹部 灰白。尾鰙上下缘各具一黑色条纹。

分布于贵州贞丰, 广西巴马, 云南富宁。

圆体爬岩鱾 Beaufortia cyclica Chen, 1980 （图 4) 测量标本 21 尾, 全长 $36.8-52.6 \mathrm{~mm}$, 体长 28.5 $-41.6 \mathrm{~mm}$ 。

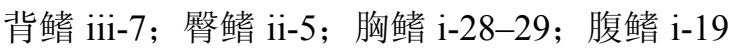
-20 。侧线鳞 $70-75$ 。

体长为体高的 5.5-7.7 倍, 为尾柄长的 12.3 17.8 倍, 为尾柄高的 10.7-14.1 倍, 为背鯺前距的 1.8 - 2.0 倍, 为腹鯺前距的 $2.3-2.6$ 倍。头长为头 高的 $2.0-2.5$ 倍, 为吻长的 $1.2-1.6$ 倍, 为眼径的 $4.7-5.7$ 倍, 为眼间距的 $1.6-2.4$ 倍。尾柄长为尾
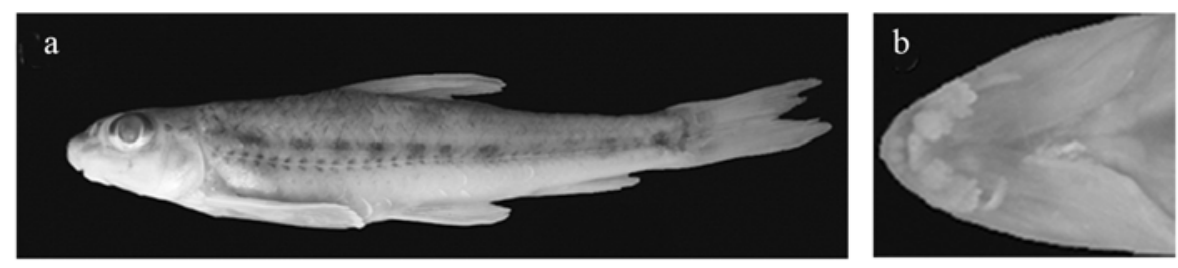

图 2 胡鮈背面(a)及口唇部(b)结构图, KIZ2005000726, 体长 $49.7 \mathrm{~mm}$

Fig. 2 Huigobio chenhsienensiss Fang (KIZ2005000726, 49.7 mm SL) lateral (a) and ventral head (b) views

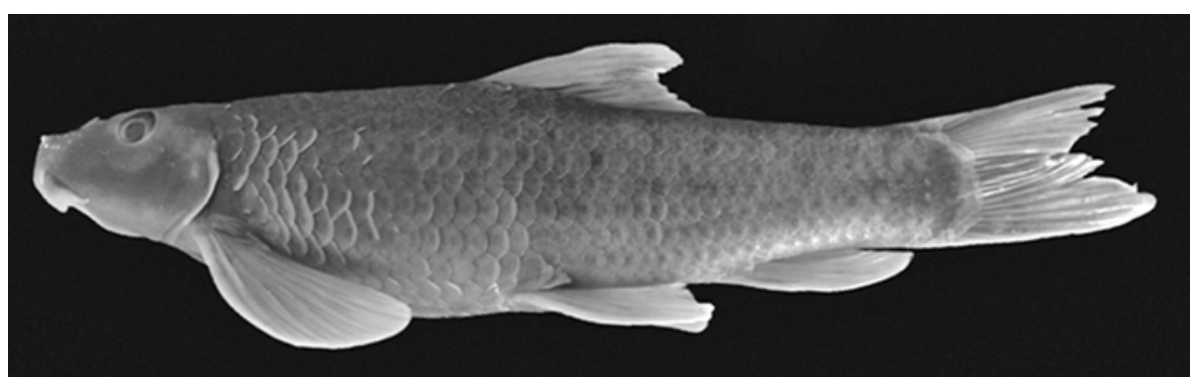

图 3 宽头盘鮈侧面图, KIZ2005000894, 体长 $88.3 \mathrm{~mm}$

Fig. 3 Discogobio laticeps Chu, Cui \& Zhou (KIZ2005000894, $88.3 \mathrm{~mm} \mathrm{SL}$ ) lateral view 
柄高的 $0.7-1.0$ 倍。

体较延长, 前段平扁; 头较宽扁; 口下位; 唇 肉质, 上唇无明显乳突; 下领前缘外露面较大, 表 面具放射状的沟和脊; 吻褶间叶具 2 对小吻须; 口 角须 1 对; 眼中等大; 鳃裂隙小; 侧线完全。

背鯺基长约与吻长相等。偶鯺平展。胸鯺起点 超过鼻孔前缘, 几乎接近吻端, 末端达到腹鯺基部 的中点稍后。腹鯺起点至臀鯺起点的距离约与至吻 端的距离相等, 基部具一肉质瓣膜。尾鯺稍长于头
长，末端斜截。

福尔马林、酒精浸泡的标本体背侧棕褐色, 腹 面灰白色, 横跨背中线具约 7 个大黑斑, 体侧具不 规则花纹。背鯺和尾鯺具两条由黑色斑点组成的条 纹。

分布于广西桂林、龙州, 云南富宁等西江水系。

\section{2 目级区系存在度分析结果}

驮娘江鱼类隶属于 4 目（鲇形目、鲤形目、鲇 形目和合鳃鱼目)。鲇形目鱼类几乎是全球性分布,

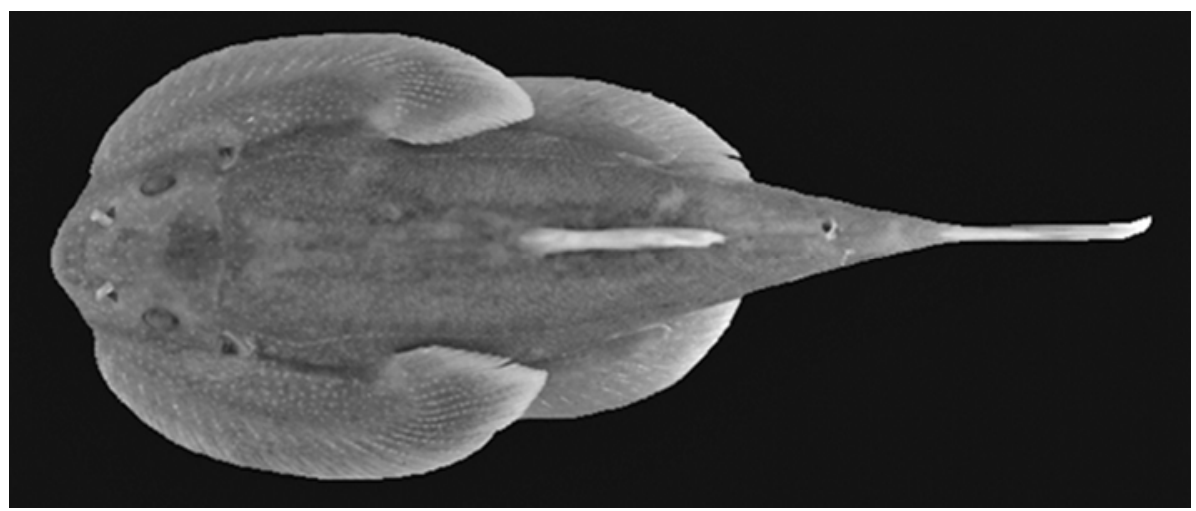

图 4 圆体爬岩鳅背面图, KIZ2005001018, 体长 $45.6 \mathrm{~mm}$

Fig. 4 Beaufortia cyclica Chen (KIZ2005001018, 45.6 mm SL) lateral view

多数生活在淡水, 以亚洲和南美洲为最多。鲤形目 鱼类是现生淡水鱼类中最大的目, 主要分布在亚洲 东南部，其次为北美洲、非洲及欧洲。鲇形目鱼类 是世界鱼类中种类最多的目, 绝大多数是海产鱼, 一般分布在温热带海区。合鳃鱼目中的合鳃鱼科为 世界性广布, 刺鳅科主要分布在非洲至亚洲的热带 淡水中。从表 1 可以看出, 第一大目鲇形目虽然科 级界元最多, 有 5 科, 但其区系存在度却排到了第 3 位，第二大目鲤形目的区系存在度也排到了第 2 位。合鳃鱼目仅有 2 科, 在驮娘江都有分布, 其区 系存在度最高, 为 $100 \%$ 。说明鱼类分布的不均匀 性和鲜明的地域特征。

\section{3 科级区系存在度分析}

从科级水平上分析, 云南驮娘江鱼类隶属于 12 科, 其中最大的科为鲤科(29 属 38 种), 其次是爬鳅科 (5 属 7 种）, 其物种数量占到驮娘江鱼类总种数的 $70.3 \%$ 。魭科在驮娘江分布有 3 属 5 种, 占驮娘江 鱼类的总种数的 $7.8 \%$ 。具 2 种的有 3 科: 鳅科（2 属) 、鳢科 (1 属) 和鮨科 (1 属), 占㭈娘江鱼 类的 $9.4 \%$ 。其余的 6 科（胡子鲇科、鲇科、鮡科、 长臀鯔科、合鳃鱼科、刺鲉科) 在驮娘江均以单属 形式出现, 占㭈娘江鱼类总种数的 $9.4 \%$ 。
表 1 驮娘江鱼类目级区系存在度

Tab. 1 Value of faunal presence of fish orders in Tuoniang River

\begin{tabular}{lcc}
\hline \multicolumn{1}{c}{$\begin{array}{c}\text { 目名 } \\
\text { Order name }\end{array}$} & $\begin{array}{c}\text { 科数 } \\
\text { Number } \\
\text { of family }\end{array}$ & $\begin{array}{c}\text { 区系存在度 } \\
\text { VFE }\end{array}$ \\
\hline 合鳃鱼目 Synbranchiformes & 2 & 100.00 \\
鲤形目 Cypriniformes & 3 & 50.00 \\
鲇形目 Siluriformes & 5 & 16.13 \\
鲇形目 Perciformes & 2 & 1.23 \\
\hline
\end{tabular}

科的区系存在度的结果与根据物种数量进行 分析的结果有着较大的差异, 这说明了动物分布的 不均匀性或具明显的地域性特征。原居第一位的鲤 科现却已排到了第 5 位，第二大科爬鳅科的区系存 在度也排到了第 7 位, 说明本地区不在鲤科和爬鳅 科的属级分化热点地区, 这与鲤科和爬鳅科在亚洲 的主要分化中心在东南亚和东亚相吻合, 而本地区 正好处于这两大地区的交汇区; 第三大科鲿科排名 第 8 位, 魭科主要分布在亚洲和非洲。长臀鯔科为 单属种的科, 是中国华南区 (也分布于海南岛) 越南特有科, 因此, 长臀鯔科的区系存在度为 $100 \%$, 排名第 1 位; 鳢科仅有 2 属, 主要分布在亚 洲南部和非洲, 鳢科在本地区仅有 1 属, 其区系存 
在度排名第 2 位; 合鳃鱼科有 4 属, 为世界性广布; 刺鳅科主要分布在非洲至亚洲的热带淡水中; 鮡科 主要分布于从土耳其至婆罗洲之间的远东地区（表 2 )。这说明一些世界性分布的科, 在驮娘江分布的 属并不很多。相反, 一些具有地方性分布特征的科, 其区系存在度 (如长臀鯔科、鳢科、合鳃鱼科、刺 鳅科) 相对较大。说明这些小科或较小科更能反映 本地区的鱼类区系特征, 即亚洲亚热带淡水鱼类区 系。

\section{4 属级区系存在度分析}

驮娘江鱼类有 45 属,其中最大的两属是盘鮈属 (Discogobio)和光唇鱼属(Acrossocheilus), 各有 4 种, 占驮娘江鱼类总种数的 $13.1 \%$; 其次为拟督属 (Pesudohemiculter)、倒刺鲃属(Spinibarbus)、鳜属
表 2 驮娘江鱼类科的区系存在度

Tab. 2 Value of faunal presence of fish families in Tuoniang River

\begin{tabular}{|c|c|c|}
\hline 科名 & 属数 & 区系存在度 \\
\hline Family name & Number of genus & VFP \\
\hline 长臀鮠科 Cranoglanididae & 1 & 100.00 \\
\hline 鳢科 Channidae & 1 & 50.00 \\
\hline 合鰓鱼科 Synbranchidae & 1 & 25.00 \\
\hline 刺鳅科 Mastacebelidae & 1 & 25.00 \\
\hline 鲤科 Cyprinidae & 29 & 13.81 \\
\hline 鱾科 Cobitidae & 2 & 11.11 \\
\hline 爬鱾科 Balitoridae & 4 & 10.81 \\
\hline 鲿科 Bagridae & 3 & 10.00 \\
\hline 鲇科 Siluridae & 1 & 8.33 \\
\hline 胡子鲇科 Clariidae & 1 & 7.69 \\
\hline 鮡科 Sisoridae & 1 & 5.00 \\
\hline 鮨科 Serranidae & 1 & 1.61 \\
\hline
\end{tabular}

表 3 驮娘江鱼类属的区系存在度

Tab. 3 Value of faunal presence of fish genus in Tuoniang River

\begin{tabular}{|c|c|c|c|c|c|}
\hline 属名 Genus name & $\begin{array}{c}\text { 种数 } \\
\text { Number } \\
\text { of species }\end{array}$ & $\begin{array}{c}\text { 区系存在度 } \\
\text { VFP }\end{array}$ & 属名 Genus name & $\begin{array}{c}\text { 种数 } \\
\text { Number } \\
\text { of species }\end{array}$ & $\begin{array}{c}\text { 区系存在度 } \\
\text { VFP }\end{array}$ \\
\hline 红鲌属 Erythroculter & 1 & 100.00 & 鱲属 Zacco & 1 & 14.29 \\
\hline 叶结鱼属 Parator & 1 & 100.00 & 蛇鮈属 Saurogobio & 1 & 14.29 \\
\hline 拟䱗属 Pseudohemiculter & 2 & 50.00 & 泥鳅属 Misgurnus & 1 & 14.29 \\
\hline 胡鮈属 Huigobio & 1 & 50.00 & 白甲鱼属 Onychostoma & 2 & 12.50 \\
\hline 似鱤属 Luciocyprinus & 1 & 50.00 & 鲫属 Carassius & 1 & 12.50 \\
\hline 原鲤属 Procypris & 1 & 50.00 & 黄鳝属 Monopterus & 1 & 10.00 \\
\hline 华平鳅属 Sinohomaloptera & 1 & 50.00 & 鲮属 Cirrhinus & 1 & 9.09 \\
\hline 瓣结鱼属 Folifer & 1 & 33.33 & 华吸鳅属 Sinogastromyzon & 1 & 9.09 \\
\hline 卷口鱼属 Ptychidio & 1 & 33.33 & 鳢属 Channa & 2 & 7.14 \\
\hline 唇鱼属 Semilabeo & 1 & 33.33 & 间吸鳅属 Hemimyzon & 1 & 7.14 \\
\hline 长臀鯔属 Cranoglanis & 1 & 33.33 & 鳠属 Hemibagrus & 2 & 6.90 \\
\hline 盘鮈 Discogobio & 4 & 30.77 & 鲇属 Silurus & 1 & 6.67 \\
\hline 倒刺鲃属 Spinibarbus & 2 & 28.57 & 鮸属 Leiocassis & 1 & 6.67 \\
\hline 鱐属 Siniperca & 2 & 22.22 & 银鮈属 Squalidus & 1 & 6.25 \\
\hline 孟加拉鲮属 Bangana & 2 & 20.00 & 鳅鮀属 Gobiobotia & 1 & 5.56 \\
\hline 爬岩鳅属 Beaufortia & 2 & 20.00 & 鲤属 Cyprinus & 1 & 3.85 \\
\hline 马口鱼属 Opsariichthys & 1 & 20.00 & 鱊属 Acheilognathus & 1 & 2.70 \\
\hline 华沙鳅属 Sinibotia & 1 & 20.00 & 胡子鲇属 Clarias & 1 & 1.72 \\
\hline 华鳊属 Sinibrama & 1 & 16.67 & 刺鳅属 Mastacembelus & 1 & 1.64 \\
\hline 鱽属 Xenocypris & 1 & 16.67 & 纹胸鮡属 Glyptothorax & 1 & 1.52 \\
\hline 光唇鱼属 Acrossocheilus & 4 & 16.00 & 墨头鱼属 Garra & 1 & 1.16 \\
\hline 鳃属 Hemibarbus & 2 & 14.29 & 南鳅属 Schistura & 1 & 0.55 \\
\hline 黄颡鱼属 Pelteobagrus & 2 & 14.29 & & & \\
\hline
\end{tabular}

(Siniperca)、孟加拉鲮属(Bangana)、爬岩鱾属 (Beaufortia)、鱼骨属 (Hemibarbus)、黄颡 鱼属 (Pelteobagrus)、白甲鱼属 (Onychostoma)、鳢属 (Channa)和鳠属(Hemibagrus), 各有 2 种, 占驮娘 江鱼类总种数的 $32.8 \%$ 。其他的属均为单种属, 占 到驮娘江鱼类总种数的 $54.1 \%$ 。
由于分类阶元的降低，鱼类地域性分布渐趋明 显。结鱼属(Parator)和红鲌属(Erythroculter)为单种 属, 区系存在度为 $100 \%$, 因此, 位居第 1 位。结 鱼属是中国特有属, 主要分布在珠江水系, 红鲌属 鱼类主要分布在亚洲南部。居第 2 位的属除拟䱗属 (Pseudohemiculter)外都为中国特有属：如似鱤属 
(Luciocyprinus)分布在澜沧江和珠江水系; 胡鮈属 (Huigobio)鱼类主要分布在黄河、珠江水系, 浙江 的曹娥江、甬江等独立的水系; 原鲤属(Procypris) 鱼类分布在长江中上游及西江水系; 华平鳅属 (Sinohomaloptera)鱼类则主要分布在珠江水系、海 南昌汇、云南的元江; 拟餐属(Pseudohemiculter)是 中国一越南的特有属鱼类。盘鮈属(Disogobio)、光 唇鱼属(Acrossocheilus)、鲴属(Xenocypris)和倒刺鲃 属(Spinibarbus)虽也为中国特有属, 但它们在驮娘 江分布的种数较少, 如盘鮈属 (4 种)、光唇鱼属 (4 种)、鲖属 (1 种) 和倒刺鲃属 (2 种), 因而它们 在区系存在度排序中的位置较后, 进一步说明物种 分布的不均匀性（表 3)。

上面的分析说明一些亚洲性分布的属, 在驮娘 江分布的种并不很多; 相反, 一些具有地方性分布 特征的属, 其区系存在度相对较大。说明这些地方 性分布的属更能反映驮娘江地区的鱼类区系特征。

一些广泛分布的种类在驮娘江的区系存在度 较低, 而地方性物种和单种属在驮娘江流域则有较 高的区系存在度。

Chen（1998）将中国淡水鱼类分为老第三纪原 始类群、北方冷水性类群、东亚类群、南方类群和 青藏高原类群五大类类群。(1) 在㭈娘江流域缺乏 以雅罗鱼亚科为代表的“北方冷水性类群”和以鲤科
裂腹鱼亚科、爬鳅科条鳅亚科高原䱊属和鲇形目鮡 科的鰋鮡鱼类为代表的“青藏高原类群”鱼类。(2) 鲤科的鲢亚科、鲌亚科、鱽亚科、鮈亚科、鱾鮀亚 科、雅罗鱼东亚类群和鲜亚科，魭科、鮨科为“东 亚类群”的代表。在驮娘江流域有 20 种, 但只有鲌 亚科的红鲌属具有较高的区系存在度，为 $100 \%$, 其他科和亚科的属级区系存在度均未达到 $70 \%$ 。 （3）以鲤科鲃亚科、野鲮亚科为代表的“老第三纪 类群”各有 11 种和 10 种, 分别约占总种数的 $18.3 \%$ 和 $16.7 \%$; 但其属级区系存在度较低, 仅有鲃亚科 的结鱼属有较高的区系存在度, 为 $100 \%$ 。鳅科、 爬鳅科、鲇形目胡子鲇科、长臀鯔科、鮡科, 鲇形 目鳢科、合鳃鱼目刺鳅科也可以划入这一类型，共 有 14 种, 约占总种数的 $23.3 \%$; 各科的属级区系存 在度并不高, 最高的为长臀鮠属, $33.3 \%$ 。但其科 级区系存在度却高于其他类群。“老第三纪类群”在 鱼类区系中是最大的类群。

致谢：感谢云南省富宁县农业局对野外考察的 大力支持。中国科学院昆明动物研究所陈自明博 士、杨剑参加了野外考察, 崔桂华高级工程师、和 孟妮在查看标本的过程中给予了诸多帮助, 在此一 并表示感谢!

\section{参考文献:}

Chen YY. 1998. Fauna Sinica (Osteichthyes: Cypriniformes II) [M]. Beijing: Science Press. [陈宜喻. 1998. 中国动物志 - 硬骨鱼纲 - 鲤形目 (中 卷). 北京: 科学出版社.]

Chen YY. 1998. The Fishes of the Hengduan Mountains Region[M]. Beijing: Science Press. [陈宜瑜. 1998. 横断山区鱼类. 北京: 科学出版社.]

Chu XL, Chen YR. 1989. The Fishes of Yunnan, China, Part I [M]. Beijing: Science Press. [禇新洛, 陈银瑞. 1989. 云南鱼类志(上册). 北京: 科 学出版社.]

Chu XL, ChenYR. 1990. The Fishes of Yunnan, China, Part II [M]. Beijing: Science Press. [禇新洛, 陈银瑞. 1990. 云南鱼类志(下册). 北京: 科 学出版社.]

Chu XL, Zheng BS, Dai DY. 1999. Fauna Sinica (Osteichthyes: Siluriformes)[M]. Beijing: Science Press. [禇新洛, 郑葆珊, 戴定远. 1999. 中国动物志 (硬骨鱼纲・鲇形目). 北京: 科学出版社.]

Froese R, Pauly D. 2007. Fish Base. World Wide Web Electronic Publication[EB]. www.fishbase.org, version (08/2007).

Gao DX. 2006. The actuality of the Tuoniang River nature reserve and countermeasures in Funing [J]. Forestry Construction, 4: 25-28. [高德 祥. 2006. 富宁驮娘江自然保护区现状及保护对策. 林业建设, 4: 25-28.]
Jiang XL. 2000. The mammals of Wuliang Mountain and Zoogeographical Analysis [D]. Ph.D. thesis, Kunming Institute of Zoology, CAS. [蒋学 龙. 2000. 景东无量山哺乳动物及区系地理学研究. 中国科学院昆 明动物研究所博士学位论文.]

Wu XW. 1963. The Fish of Cyprinidae in China, Part I [M]. Shanghai Science \& Technology Publishing House. [伍献文. 1963. 中国鲤科鱼 类志(上卷). 上海: 上海科学技术出版社.]

Wu XW. 1977. The Fish of Cyprinidae in China, Part II [M]. Shanghai Science \& Technology Publishing House. [伍献文. 1977. 中国鲤科鱼 类志(下卷). 上海: 上海人民出版社.]

Yue PQ et al. 2000. Fauna Sinica (Osterichthyes: CypriniformesIII) [M]. Beijing: Science Press. [乐佩琦等. 2000. 中国动物志 - 硬骨鱼纲 - 鲤 形目 (下卷). 北京: 科学出版社.]

Zheng BS. 1981. Freshwater Fishes Guangxi [M]. Nanning: Guangxi People’s Publishers. [郑葆珊. 1981. 广西鱼类志. 南宁: 广西人民出 版社.]

Zheng CY. 1989. The Fishes of Pearl River [M]. Beijing: Science Publishing Company. [郑慈英. 1989. 珠江鱼类志. 北京: 科学出版社.]

Zhu SQ. 1989. The loaches of the subfamily Nemacheilinae in China (Cypriniformes: Cobitidae) $[\mathrm{M}]$. Nanjing: Jiangsu Science \& 
Technology Publishing House. [朱松泉. 1989. 中国条鳅志. 江苏科 学技术出版社.]

Zhu SQ. 1995. Synopsis of Freshwater Fishes of China [M]. Nanjing:
Jiangsu Science and Technology Publishing House. [朱松泉. 1995. 中

国淡水鱼类检索. 江苏科学技术出版社.]

附录 I 驮娘江鱼类分布名录

Appendix I The distribution and composition of fish in Tuoniang River

\begin{tabular}{|c|c|c|c|c|c|}
\hline 中文名 Chinese name & 拉丁名 Scientific name & $\begin{array}{c}\text { 特有性 } \\
\text { Endemism }\end{array}$ & $\begin{array}{c}\text { 驮娘江 } \\
\text { Tuoniang } \\
\text { river }\end{array}$ & $\begin{array}{c}\text { 那马河 } \\
\text { Nama } \\
\text { river }\end{array}$ & $\begin{array}{c}\text { 谷拉河 } \\
\text { Gula river }\end{array}$ \\
\hline I . 鲤形目 & CYPRINIFORMES & & & & \\
\hline 鲤科 & Cyprinidae & & & & \\
\hline 鿕亚科 & Danioninae & & & & \\
\hline 1. 马口鱼 & Opsariichthys bidens Günther & & + & $\mathrm{P}$ & $\mathrm{P}$ \\
\hline 2. 宽鯺鱲 & Zacco platypus (Temminck et Schlegel) & & $\mathrm{P}$ & ++ & $\mathrm{P}$ \\
\hline 雅罗鱼亚科 & Leuciscinae & & & & \\
\hline 3. 草鱼 & Ctenopharyngodon idella (Valenciennes) & I & & $\mathrm{H}$ & \\
\hline 4. 赤眼鯂 & Squaliobarbus curriculus (Richardson) & I & $\mathrm{H}$ & $\mathrm{H}$ & \\
\hline 5. 鲩 & Ochetobius elongates (Kner) & I & $\mathrm{P}$ & & \\
\hline 6. 鳡 & Elopichthys bambusa (Richardson) & I & $\mathrm{P}$ & & \\
\hline 7. 鯮 & Luciobrama macrocephalus (Lacépède) & I & $\mathrm{P}$ & & \\
\hline 鲢亚科 & Hypophthalmichthinae & & & & \\
\hline 8. 鳙 & Aristichthys nobilis (Richardson) & I & & $\mathrm{H}$ & \\
\hline 9. 鲢 & Hypophthalmichthys molitrix (Valenciennes) & I & & $\mathrm{H}$ & \\
\hline 鲌亚科 & Cultrinae & & & & \\
\hline 10. 拟华鳊 & Sinibrama affinis (Vaillant) & & $\mathrm{H}$ & & \\
\hline 11. 南方拟粲 & Pseudohemiculter dispar (Peters) & & $\mathrm{H}$ & $\mathrm{H}$ & \\
\hline 12. 海南拟㯺 & P. hainanensis (Boulenger) & & $\mathrm{H}$ & $\mathrm{H}$ & \\
\hline 13. 大眼红鲌 & Erythroculter hypselonotus (Lin) & & $\mathrm{H}$ & $\mathrm{H}$ & \\
\hline 鮈亚科 & Gobioninae & & & & \\
\hline 14. 花鳃 & Hemibarbus maculates Bleeker & & + & + & \\
\hline 15. 间䱻 & H. medius Yue & & $\mathrm{H}$ & & \\
\hline 16. 麦穗鱼 & Pseudorasbora parva (Temminck et Schlegel) & I & ++ & ++ & ++ \\
\hline 17. 棒花鱼 & Abbotina rivularis (Basilewsky) & I & ++ & ++ & ++ \\
\hline 18. 银鮈 & Squalidus argentatus (Sauvage et Dabry de Thiersant) & & $\mathrm{H}$ & $\mathrm{H}$ & \\
\hline 19. 蛇鮈 & Saurogobio dabryi Bleeker & & $\mathrm{P}$ & $\mathrm{H}$ & $\mathrm{P}$ \\
\hline 20. 胡鮈 & Huigobio chenhsienensis Fang & & + & & \\
\hline 鳅鮀亚科 & Gobiobotia & & & & \\
\hline 21. 南方鱾鮀 & Gobiobotia meridionalis Chen et Tsao & & $\mathrm{P}$ & $\mathrm{H}$ & \\
\hline 鱊亚科 & Acheilognathinae & & & & \\
\hline 22. 短须䁤 & Acheilognathus barbatulus Günther & & ++ & & \\
\hline 鲖亚科 & Xenocyprinae & & & & \\
\hline 23. 银鲖 & Xenocypris argentea Günther & & & & \\
\hline 鲃亚科 & Barbinae & & & & \\
\hline 24. 叶结鱼 & Parator zonatus (Lin) & $\mathrm{E}$ & $\mathrm{H}$ & & \\
\hline 25. 瓣结鱼 & Folifer brevifilis (Peters) & & + & $\mathrm{H}$ & + \\
\hline 26. 倒刺鲃 & Spinibarbus denticulatus denticulatus (Oshima) & & $\mathrm{H}$ & $\mathrm{H}$ & \\
\hline 27. 刺鲃 & S. caldweli (Nichols) & & $\mathrm{H}$ & $\mathrm{H}$ & \\
\hline 28. 单纹似鱤 & Luciocyprinus langsoni Vaillant & & $\mathrm{H}$ & & \\
\hline 29. 南方白甲鱼 & Onychostoma gerlachi (Peters) & & + & ++ & +++ \\
\hline 30. 菱形白甲鱼 & O. ovale rhomboides (Tang) & & $\mathrm{H}$ & & + \\
\hline 31. 细身光唇鱼 & Acrossocheilus 75longates (Pellegrin et Chevey) & & $\mathrm{H}$ & & \\
\hline 32. 窄条光唇鱼 & A. stenotaeniatus Chu et Cui & $\mathrm{E}$ & $\mathrm{H}$ & $\mathrm{H}$ & \\
\hline 33. 多耙光唇鱼 & A. clivosius (Lin) & $\mathrm{E}$ & $\mathrm{H}$ & $\mathrm{H}$ & \\
\hline
\end{tabular}

(续下页) 
(接上页)

\begin{tabular}{|c|c|c|c|c|c|}
\hline 中文名 Chinese name & 拉丁名 Scientific name & $\begin{array}{c}\text { 特有性 } \\
\text { Endemism }\end{array}$ & $\begin{array}{c}\text { 㭈娘江 } \\
\text { Tuoniang } \\
\text { river }\end{array}$ & $\begin{array}{c}\text { 那马河 } \\
\text { Nama } \\
\text { river }\end{array}$ & $\begin{array}{c}\text { 谷拉河 } \\
\text { Gula river }\end{array}$ \\
\hline 34. 虹彩光唇鱼 & A. iridescens (Nichols et Pope) & & + & & + \\
\hline 野鲮亚科 & Labeoninae & & & & \\
\hline 35. 卷口鱼 & Ptychidio jordani Myers & & $\mathrm{H}$ & $\mathrm{H}$ & \\
\hline 36. 暗色唇鱼 & Semilabeo obscures Lin & & $\mathrm{H}$ & & ++ \\
\hline 37. 桂孟加拉鲮 & Bangana decora (Peters) & & $\mathrm{H}$ & $\mathrm{H}$ & \\
\hline 38. 伍氏孟加拉鲮 & B. wui (Zheng et Chen) & & $\mathrm{H}$ & $\mathrm{H}$ & \\
\hline 39. 鲮鱼 & Cirrhinus molitorella (Valenciennes) & & $\mathrm{H}$ & $\mathrm{H}$ & \\
\hline 40. 四须盘鮈 & Discogobio tetrabarbatus Lin & & + & & ++ \\
\hline 41. 云南盘鮈 & D. yunnanensis (Regan) & & & + & \\
\hline 42. 宽头盘鮈 & D. laticeps Chu, Cui et Zhou & E & & & +++ \\
\hline 43. 双珠盘鮈 & D. bismaritus Chu, Cui et Zhou & $\mathrm{E}$ & $\mathrm{H}$ & & \\
\hline 44. 东方墨头鱼 & Garra orientalis Nichols & & $\mathrm{H}$ & & + \\
\hline 鲤亚科 & Cyprininae & & & & \\
\hline 45. 乌原鲤 & Procypris merus Lin & $\mathrm{E}$ & $\mathrm{H}$ & & \\
\hline 46. 鲤 & Cyprinus carpio Linnaeus & & + & ++ & + \\
\hline 47. 鲫 & Carassius auratus auratus (Linnaeus) & & $P$ & + & $\mathrm{P}$ \\
\hline 鳅科 & Cobitidae & & & & \\
\hline 沙鳅亚科 & Botiinae & & & & \\
\hline 48. 壮体华沙鳅 & Sinibotia robusta $(\mathrm{Wu})$ & & + & $\mathrm{H}$ & \\
\hline 花鱾亚科 & Cobitinae & & & & \\
\hline 49. 泥鱾 & Misgurnus anguillicaudatus (Cantor) & & + & + & + \\
\hline 爬鱾科 & Balitoridae & & & & \\
\hline 条鯻亚科 & Nemacheilinae & & & & \\
\hline 50. 横纹南鱾 & Schistura fasciolata (Nichols et Pope) & & + & + & + \\
\hline 爬鳅亚科 & Balitorinae & & & & \\
\hline 51. 广西华平鱾 & Sinohomaloptera kwangsiensis (Fang) & & + & & + \\
\hline 52. 伍氏华吸鱾 & Sinogastromyzon wui Fang & $\mathrm{E}$ & $\mathrm{H}$ & & + \\
\hline 53. 大鯺间吸鱾 & Hemimyzon macroptera Zheng & E & & & ++ \\
\hline 腹吸鱾亚科 & Gastromyzoninae & & & & \\
\hline 54. 圆体爬岩鲉 & Beaufortia cyclica Chen & $\mathrm{E}$ & & & +++ \\
\hline 55. 条斑爬岩鱾 & B. zebroidus (Fang) & $\mathrm{E}$ & & & +++ \\
\hline II. 鲇形目 & SILURIFORMES & & & & \\
\hline 胡子鲇科 & Clariidae & & & & \\
\hline 56. 胡子鲇 & Clarias fuscus (Lacépède) & & & & + \\
\hline 鲇科 & Siluriformes & & & & \\
\hline 57. 鲇 & Silurus asotus Linnaeus & & $\mathrm{P}$ & & + \\
\hline 鮡科 & Sisoridae & & & & \\
\hline 58. 中华纹胸鮡 & Glyptothorax sinensis (Regan) & & $\mathrm{H}$ & & \\
\hline 长臀鯔科 & Cranoglanididae & & & & \\
\hline 59. 长臀鮠 & Cranoglanis bouderius bouderius (Richardson) & E & $\mathrm{H}$ & $\mathrm{H}$ & \\
\hline 魭科 & Bagridae & & & & \\
\hline 60. 斑鳠 & Hemibagrus guttatus (Lacépède) & & $\mathrm{H}$ & + & + \\
\hline 61. 大鯺鳠 & H. macropterus (Bleeker) & & $\mathrm{H}$ & & \\
\hline 62. 黄颡鱼 & Pelteobagrus fulvidraco (Richardson) & & $\mathrm{H}$ & & \\
\hline 63. 瓦氏黄滪鱼 & P. vachelli (Richardson) & & $\mathrm{H}$ & $\mathrm{H}$ & \\
\hline 64. 粗唇鮠 & Leiocassis crassilabris Günther & & $\mathrm{H}$ & $\mathrm{H}$ & \\
\hline III. 合鰓鱼目 & SYNBRANCHIFORMES & & & & \\
\hline 合鳃鱼科 & Synbranchidae & & & & \\
\hline 65. 黄鳝 & Monopterus albus (Zuiew) & & $\mathrm{H}$ & + & \\
\hline
\end{tabular}


(接上页)

\begin{tabular}{|c|c|c|c|c|c|}
\hline 中文名 Chinese name & 拉丁名 Scientific name & $\begin{array}{c}\text { 特有性 } \\
\text { Endemism }\end{array}$ & $\begin{array}{c}\text { 驰娘江 } \\
\text { Tuoniang } \\
\text { river }\end{array}$ & $\begin{array}{c}\text { 那马河 } \\
\text { Nama } \\
\text { river }\end{array}$ & $\begin{array}{c}\text { 谷拉河 } \\
\text { Gula river }\end{array}$ \\
\hline 刺鳅科 & Mastacembelidae & & & & \\
\hline 66. 大刺鳅 & Mastacembelus armatus (Lacépède) & & $\mathrm{H}$ & + & + \\
\hline IV. 鲈形目 & PERCIFORMES & & & & \\
\hline 丽鱼科 & Cichlidae & & & & \\
\hline 67. 尼罗罗非鱼 & Tilapia nilotica (Linnaeus) & I & & $\mathrm{P}$ & \\
\hline 塘鳢科 ～～～～～～～～ & Eleotridae & & & & \\
\hline 68. 小黄鲜鱼 & Micropercops swinhonis (Günther) & I & & $\mathrm{P}$ & \\
\hline 鰕虎鱼科 & Gobiidae & & & & \\
\hline 69. 子陵吻鰕鯱鱼 & Rhinogobius giurinus (Rutter) & I & & & + \\
\hline 70. 褐吻鰕鯱鱼 & Rhinogobius brunneus Temminck et Schlegel & I & ++ & & + \\
\hline 鳢科 & Channidae & & & & \\
\hline 71. 月鳢 & Channa asiatica (Linnaeus) & & & + & \\
\hline 72. 乌鳢 & C. argus (Cantor) & & & + & \\
\hline 鮨科 & Serranidae & & & & \\
\hline 73. 大眼鳜 & Siniperca kneri Garmam & & $\mathrm{H}$ & + & \\
\hline 74. 斑䱻 & S. scherzeri Steindachner & & $\mathrm{H}$ & $\mathrm{H}$ & + \\
\hline
\end{tabular}

E: 西江水系特有种 (Endemic species)； I: 外来种 (Introduced species)； H: 历史记录 (Historical record);

P: 推测可能有分布的种类(Probably distributed species); + 偶见种(rare species); ++ 常见种(Common species); +++ 优势种(Dominant species)。

\section{诚邀英文稿件，诚谢 2007 年度作者和审稿人}

在中国科学技术信息研究所《2007 年版中国科技期刊引证报告（核心版)》中，《动物学研究》影响因 子为 0.649 , 在 59 种生物学类期刊中排名第 20 位。在中国科学文献计量评价研究中心 《中国学术期刊综 合引证年度报告 (2007)》中, 本刊影响因子为 $0.809,5$ 年影响因子 0.938 , 他引总引比 $0.94, h$ 指数 11 。

2007 年编辑部收到来稿 393 篇, 其中英文来稿 54 篇; 英文来稿中, 国外来稿 33 篇, 比 2006 年增加 8 篇。为此，我们对 2007 年向本刊投稿的作者致以诚挚地感谢！并进一步鼓励作者投英文稿件。

过去的一年, 本刊刊发稿件 105 篇, 其中刊发英文来稿 29 篇, 占发表稿件的 $28 \%$ 。收稿至发表的年 平均周期为 166 天，接受至发表的年平均周期为 85 天。每一篇论文的刊发，每一篇论文的发表周期都与 本刊的审稿人的鼎力支持密不可分。对此, 我们对审稿人为本刊付出的心血表示崇高地敬意! 为表达我们 由衰的感激之情, 现以姓氏拼音为序, 谨列出 2007 年度的审稿人。

\begin{tabular}{|c|c|c|c|}
\hline 鲍毅新 & 浙江师范大学生态研究所 & 费 俭 & 同济大学生命科学与技术学院 \\
\hline 蔡 谨 & 浙江大学玉泉校区材化学院生物工程研究所 & 冯 & 东北师范大学城市与环境科学学院 \\
\hline 陈 鹏 & 东北师范大学 & 高建军 & 云南大学生物资源保护与利用重点实验室 \\
\hline 陈其才 & 华中师范大学生命科学学院 & 高 艳 & 中国科学院上海生命科学院植生所 \\
\hline 陈学新 & 浙江大学应用昆虫学研究所 & 耿宝荣 & 福建师范大学生命科学学院 \\
\hline 裙建新 & 中国医学科学院血液学研究所 & 龚大洁 & 西北师范大学 \\
\hline 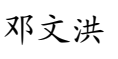 & 北京师范大学生命科学学院 & 顾福康 & 华东师范大学生命科学学院 \\
\hline 丁长青 & 中国科学院动物研究所 & 郝家胜 & 安徽师范大学生命科学学院 \\
\hline 丁 平 & 浙江大学紫金港校区生命科学学院 & 胡慧建 & 华南濒危动物研究所 \\
\hline 何立华 & 中国科学技术大学生命科学院视觉实验室 & 黄乘明 & 广西师范大学生命科学学院 \\
\hline
\end{tabular}

(下转第 94 页) 